\title{
Ion-Induced Emission of Amino Acid Molecular Ions from Thin Films
}

\author{
Y. Nakata, Y. Honda, S. Ninomiya*, J. Matsuo* \\ Department of Nuclear Engineering, Kyoto University, Sakyo, Kyoto, 606-8501, Japan \\ Fax: 81-75-753-3571, e-mail: yukai@nucleng.kyoto-u.ac.jp \\ *Quantum Science and Engineering Center, Kyoto University, Gokasho, Uji, 611-0011, Japan \\ Fax: 81-774-38-3978, e-mail: ninomiya@nucleng.kyoto-u.ac.jp
}

\begin{abstract}
Secondary ion emission from bio-molecular samples bombarded with ion beams was investigated. Emitted ions from arginine amino acid thin films were measured using a time-of-flight method under $10 \mathrm{keV} \mathrm{Ar}$ and $500 \mathrm{keV} \mathrm{Au}$ ion bombardments. For $500 \mathrm{keV}$ ion irradiation, the molecular ion yield was about $1 \times 10^{-3}$ molecules/ion, which was 2 orders of magnitude larger than with 10 $\mathrm{keV}$ ion irradiation. As there are very few data on sputtering of bio-molecules under sub-MeV-energy range, the present work will contribute to understanding of emission mechanism caused by ion-beam irradiation.
\end{abstract}

Key words: amino acid, sputtering, electronic excitation

\section{INTRODUCTION}

Fast heavy ion impact $\left(\mathrm{v} \geq \mathrm{e}^{2} / \mathrm{h}, \mathrm{v}_{\mathrm{B}}\right.$ : the Bohr velocity) on a solid surface induces electronic excitation around its trajectory and the excitation energy can be converted to atomic and molecular emission from the surface. This process is referred to as electronic sputtering. Emission mechanism of the electronic sputtering is quite different from that of nuclear sputtering, which is dominant process at projectile energies below several hundreds of $\mathrm{keV}$. We have investigated secondary ions under MeV-energy ion bombardment using the time-of-flight method and found that not only atomic ions but also large cluster ions were emitted from semiconductors and insulators $[1,2]$. The experimental results demonstrated that the cluster ion emission was enhanced by the electronic excitation for insulator targets such as $\mathrm{Al}_{2} \mathrm{O}_{3}$ and $\mathrm{SiO}_{2}$.

For organic materials, Macfarlane and coworkers discovered that intact bio-molecular ions were sputtered by fast heavy ion irradiation [3]. Time-of-Flight mass spectrometry using fission fragments from a ${ }^{252} \mathrm{Cf}$ source, referred to as plasma desorption mass spectrometry (PDMS), has been successfully employed to mass-analyze bio-molecular ions. The electronic sputtering of bio-molecules has been experimentally investigated in detail by Uppsala group [4-6] and the emission mechanism was explained by sum of impulses induced by the fast heavy ion irradiation in solids [7]. Although most of the studies were devoted to the relatively high-energy range above several tens of $\mathrm{MeV}$, there are very few data on sputtering at the projectile energies between 0.1 and $10 \mathrm{MeV}$. In this energy range, the emission mechanism of bio-molecules is not clear because both the nuclear and electronic stopping powers are competing with each other.

In this study, we measured secondary ions from arginine amino acid thin films bombarded with 500
$\mathrm{keV}$ ions using a time-of-flight mehod and compared the secondary ion intensites with those by $10 \mathrm{keV}$ ion bombardment. For better understanding of the ion formation, the optimized structure and electronic structure of the arginine molecule were obtained by ab initio molecular orbital calculation using the Gaussian 98 program [8].

\section{EXPERIMENTAL}

\subsection{Sample}

Arginine (molecular weight 174.2) is one of the 20 standard amino acids and has been used as targets for mass analyses such as PDMS, secondary ion mass spectrometry (SIMS) and matrix-assisted laser desorption/ionization mass spectrometry (MALDI-MS). Thus, the results obtained in this experiment can be compared with the early data in the conventional mass spectroscopic methods. The arginine sample was purchased from Nacalai Tesque (Japan) and used without further purification. The sample powder $\left(\begin{array}{ll}\mathrm{g}\end{array}\right)$ was dissolved in $8 \mathrm{~mL}$ of water and the solution was used for thin film preparation. Water used in this experiment was purified using an Arium ultra pure water system (Sartorius, Germany).

\subsection{Spin-coating technique}

We prepared arginine thin films by using the spin-coating technique, which can produce smooth and thin films. This technique has been used to obtain bio-molecular thin films [9]. In this study, a $10 \mu \mathrm{L}$ aqueous solution of arginine was deposited on a rotating Si wafer which was rinsed by water and acetone using ultra sonic cleaner in advance. The smoothness and thickness of the film were measured using a contact surface profiler (Dektak3, ULVAC, Japan), a laser microscope (VK8500, KEYENCE, Japan) and an ellipsometer. The film thickness was about $200 \mathrm{~nm}$ and the surface roughness was below a few tens of nanometers. The 


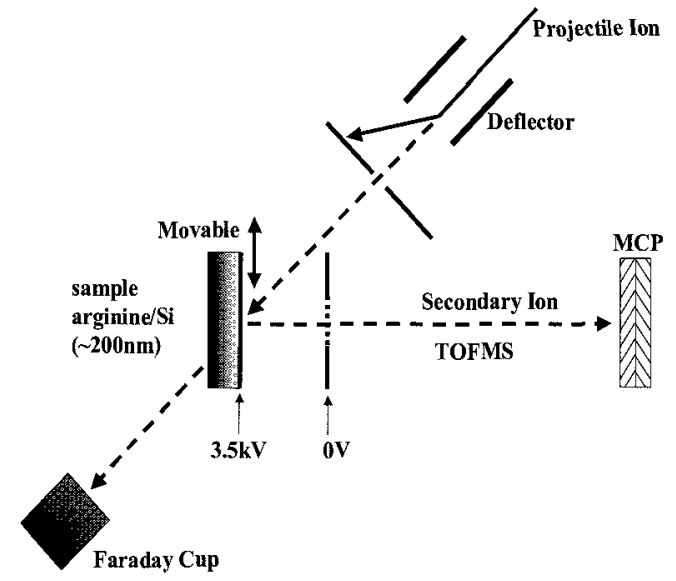

Fig. 1 Experimental setup.

spin-coating procedure was performed in a clean room under humidity control because the film thickness and smoothness seem to be sensitive to the air humidity.

\subsection{Time-of-Flight mass spectrometry}

Fig. 1 shows a schematic diagram of the experimental setup. $500 \mathrm{keV} \mathrm{Au}^{+}$ion beams $\left(\mathrm{v} / \mathrm{v}_{\mathrm{B}}=\sim 0.3\right)$ provided by Kyoto University's 1.7 MV tandem accelerator were used to irradiate the arginine films. The beams were chopped to a width of $50 \mathrm{~ns}$ every $100 \mu \mathrm{s}$ and incident on the films at $20^{\circ}$ to the surface normal after being collimated to a diameter of $2 \mathrm{~mm}$. The secondary ions were extracted with a kinetic energy of $3.5 \mathrm{keV}$ and detected by a microchannel plate detector after passing through a field-free drift region. Mass analysis of secondary ions was performed using a linear time-of-flight technique in a vacuum of $2 \times$ $10^{-5} \mathrm{~Pa}$.

Low-energy ion beams were also employed as primary ion beams. The experimental method is described in detail elsewhere [10]. $10 \mathrm{keV} \mathrm{Ar}^{+}$ion beams $\left(\mathrm{v} / \mathrm{v}_{\mathrm{B}}=\sim 0.1\right)$ were chopped to a width of $5 \mu \mathrm{s}$ every $200 \mu \mathrm{s}$ by applying a voltage of $700 \mathrm{~V}$ between parallel electrodes. The pulsed ion beam was incident on the arginine films at $45^{\circ}$ with respect to the surface normal. Secondary ions were again chopped by the secondary-ion deflector, which is known as the interleaved comb ion (mass) deflection gate. This chopper is composed of parallel thin wires and is mounted between the sample and the secondary-ion detector. Secondary ions were first accelerated to a kinetic energy of 2 $\mathrm{keV}$ and then chopped to a width of 200 ns every $200 \mu \mathrm{s}$ by applying a voltage below $500 \mathrm{~V}$ between the wires. The secondary ions were detected with a channel electron multiplier set on the axis of the sample surface normal. The base and working pressure in the secondary-ion analytical chamber was $2 \times 10^{-6}$ and $2 \times 10^{-5} \mathrm{~Pa}$, respectively.

\section{RESULTS AND DISCUSSION \\ Positive ion mass spectrum of arginine}
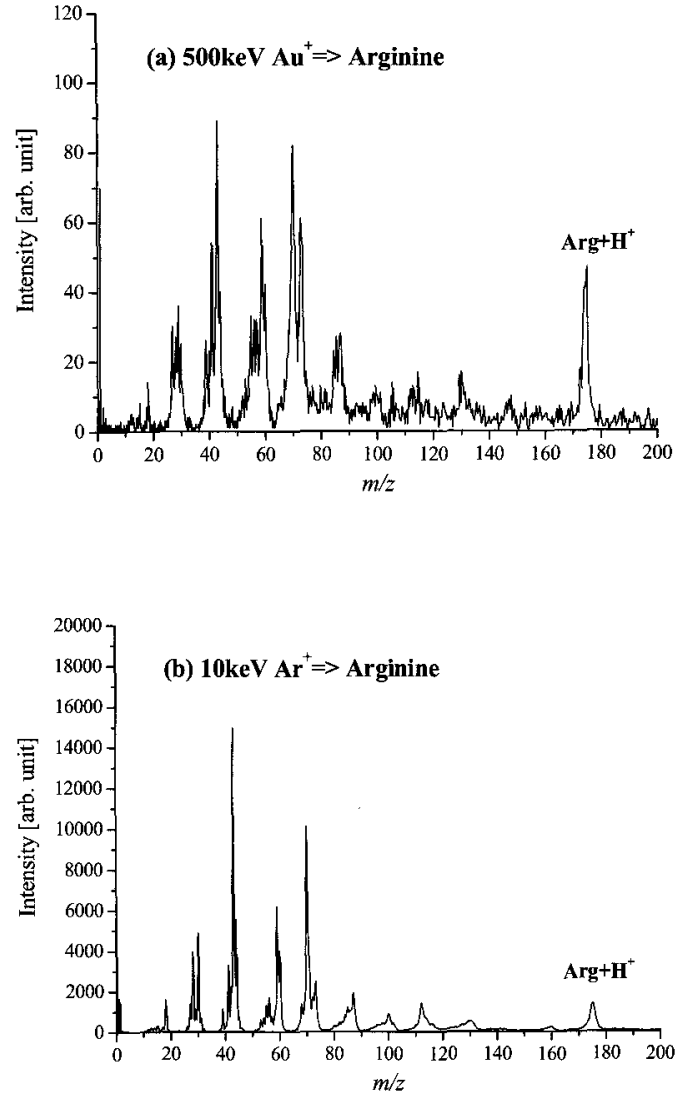

Fig. 2 Positive-ion spectra of arginine bombarded with $500 \mathrm{keV}$ ions (a) and $10 \mathrm{keV}$ ions (b).

bombarded with $500 \mathrm{keV}$ ions is shown in Fig. 2 (a). Protonated arginine ions $(\mathrm{m} / \mathrm{z} 175)$ as well as characteristic fragment ions at $\mathrm{m} / \mathrm{z} 43\left(\mathrm{CH}_{3} \mathrm{~N}_{2}{ }^{+}\right), 60$ $\left(\mathrm{CH}_{5} \mathrm{~N}_{3}{ }^{+}\right)$and $70\left(\mathrm{C}_{4} \mathrm{H}_{8} \mathrm{~N}^{+}\right)$were detected. The spectrum is in good agreement with the SIMS and the PDMS spectra $[11,12]$. The protonated arginine ion is a feature of the positive-ion spectra for amino acid molecules under ion irradiation because the amino group $\left(-\mathrm{NH}_{2}\right)$ of each amino acid molecule is, in general, easily protonated. To gain a better understanding of the protonated arginine ion, the structure of the arginine molecule was optimized with the Gaussian program [8]. Fig. 3 shows the arginine structure and its highest occupied molecular orbital determined by the calculation. It was found that the guanidino group $\left(\mathrm{H}_{2} \mathrm{NC}(=\mathrm{NH})-\mathrm{NH}-\right)$ of the arginine molecule is prone to be protonated. In fact, the guanidino group of the arginine molecule provides higher proton affinity (about $10.5 \mathrm{eV} / \mathrm{atom}$ ) than the amino group [13]. Emitted negative ions were also measured under $500 \mathrm{keV}$ ion bombardment. Arginine molecules were observed in the form of deprotonated ions $(\mathrm{m} / \mathrm{z} 173)$ in the negative-ion spectrum. The fragment ion spectrum is similar to 


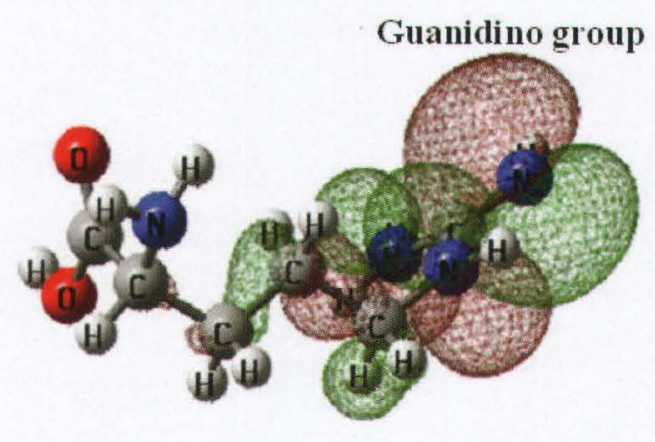

Fig. 3 The arginine structure and the highest occupied molecular orbital calculated by the Gaussian program [8].

that in the positive-ion mode, although the negative fragment ions were not clearly identified. It is interesting to note that, in the negative-ion spectrum, the intensity ratios of the fragment peaks to the arginine peak were lower than those in the positive-ion mode, indicating that the negative fragment ions were relatively unstable compared to the positive ones.

An example of positive-ion spectra obtained for $10 \mathrm{keV}$ ion impacts is shown in Fig. 2 (b). The spectrum seems to be similar to that of Fig. 2 (a). However, it is noted that, for $500 \mathrm{keV}$ ion irradiation, the intensity ratios of the fragment ions to the protonated arginine ions are lower than those in $10 \mathrm{keV}$. In addition, the estimated yield of the protonated arginine ions produced by $500 \mathrm{keV}$ ions is about $1 \times 10^{-3}$ molecules/ion, which is two orders of magnitude larger than with $10 \mathrm{keV}$ Ar ion bombardment $\left(1 \times 10^{-5}\right.$ molecules/ion $)$. These results show that the $500 \mathrm{keV}$ ion beam irradiation promotes the production of protonated arginine ions with reduction in fragment ions compared to $10 \mathrm{keV}$ ion beam irradiation. This study has only started recently and we plan to measure molecular ion yields for various bio-molecular samples and projectile energies and species.

\section{SUMMARY}

We studied secondary ion emission from arginine amino acid films bombarded with $500 \mathrm{keV}$ $\mathrm{Au}$ ions and compared the ion intensities with those observed under $10 \mathrm{keV}$ Ar ion bombardment. A high sputtering yield of the arginine ions and a reduction in ion fragmentation were observed for $500 \mathrm{keV} \mathrm{Au}$ ions. The experimental results indicate that, for the $500 \mathrm{keV}$ ion bombardment, the projectile energy was used more efficiently for desorption and ionization of arginine molecules than at $10 \mathrm{keV}$. Further experiments on projectile energy dependence of sputtering yields for various samples are needed to understand the details of the emission mechanism.

\section{REFERENCES}

[1] S. Ninomiya, C. Imada, M. Nagai, Y. Nakata, N. Imanishi, Phys. Rev. A, 70, 042903 (2004).

[2] S. Ninomiya, N. Imanishi, Vacuum, 73, 79 (2004).

[3] D. E. Torgerson, R. P. Skowronski, amd R. D. Macfarlane, Biochem. Biophys. Res. Commun., 60, 616 (1974).

[4] P. Hakansson, E. Jayasinghe, A. Johansson, I. Kamensky, and B. Sundqvist, Phys. Rev. Lett., 47, 1227 (1981).

[5] B. Sundqvist, Nucl. Instr. and Meth. B, 48, 517 (1990).

[6] A. Hedin, P. Häkansson, and B. Sundqvist, Nucl. Instr. and Meth. B, 22, 491 (1987).

[7] R. E. Johnson, B. U. R. Sundqvist, A. Hedin, D. Fenyo, Phys. Rev. B, 40, 49 (1989).

[8] M. J. Frisch, G. W. Trucks, H. B. Schlegel, G. E. Scuseria, M. A. Robb, et. al., Gaussian 98, Gaussian Inc., Pittsburgh, PA, 1998.

[9] G. Säve, P. Häkansson, B. U. R. Sundqvist, U. Jönsson, Nucl. Instr. and Meth. B, 26, 571 (1987).

[10] S. Ninomiya, Y. Nakata, K. Ichiki, T. Seki, T. Aoki, J. Matsuo, Nucl. Instr. and Meth. B. 256, 493 (2007).

[11] B. T. Chait, W. C. Agosta and F. H. Field, Int. J. Mass Spectrom. and Ion Phys. 39, 339 (1981).

[12] A. Benninghoven and W. Sichtermann, Anal. Chem., 50, 1180 (1978).

[13] A. G. Harrison, Mass Spectrom. Rev., 16, 201 (1997).

[14] A. Hedin, P. Häkansson, M. Salehpour, and B. U. R. Sundqvist, Phys. Rev. B, 35, 7377 (1987).

[15] J. F. Ziegler, J. P. Biersack, and U. Littmark, The Stopping and Range of Ions in Solids, Pergamon Press, Ner York, 1985.

(Received December 10, 2006;Accepted May 15, 2007) 